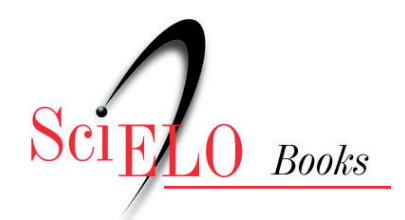

\title{
2. Educação de jovens e adultos concepções, avaliações e políticas públicas no contexto do município de Salvador-BA
}

\author{
Gilvanice Barbosa da Silva Musial \\ Rejane de Oliveira Alves \\ Sandra Maria Marinho Siqueira \\ Marize Souza Carvalho \\ Uilma Rodrigues de Matos
}

\section{SciELO Books / SciELO Livros / SciELO Libros}

MUSIAL, G.B.S., ALVES, R.O., SIQUEIRA, S.M.M., CARVALHO, M.S., and MATOS, U.R. Educação de jovens e adultos: concepções, avaliações e políticas públicas no contexto do município de SalvadorBA. In: PAIVA, J., comp. Aprendizados ao longo da vida: sujeitos, políticas e processos educativos [online]. Rio de Janeiro: EDUERJ, 2019, pp. 41-65. Pesquisa em educação/Educação ao longo da vida series. ISBN: 978-65-990364-9-1. https://doi.org/10.7476/9786599036491.0003.

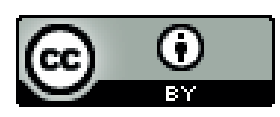

All the contents of this work, except where otherwise noted, is licensed under a Creative Commons Attribution 4.0 International license.

Todo o conteúdo deste trabalho, exceto quando houver ressalva, é publicado sob a licença Creative Commons Atribição $\underline{4.0}$.

Todo el contenido de esta obra, excepto donde se indique lo contrario, está bajo licencia de la licencia Creative Commons $\underline{\text { Reconocimento } 4.0 .}$. 


\section{Educação de jovens e adultos: concepções, avaliações e políticas públicas no contexto do município de Salvador-BA}

Gilvanice Barbosa da Silva Musial, Rejane de Oliveira Alves, Sandra Maria Marinho Siqueira, Marize Souza Carvalho e Uilma Rodrigues de Matos

\section{Introduçáo}

Historicamente, o campo da educação de jovens e adultos (EJA) tem ocupado um lugar secundário nas políticas públicas de educaçáo tanto no que se refere ao seu financiamento quanto no que concerne à formação de professores para atuar nessa modalidade. Trata-se de um lugar marcado por programas emergenciais e descontínuos que não refletiram a garantia do direito à educação, conforme previsto na Constituição Federal brasileira de 1988 (Di Pierro e Haddad, 2015).

As características mais comumente associadas à EJA são, em grande parte, marcadas pelo preconceito (Galvão e Di Pierro, 2013; Sales e Paiva, 2014). Essa modalidade é vista como um lugar onde tudo é permitido: a improvisaçáo, o amadorismo, $\mathrm{o}$ trabalho realizado de qualquer jeito com qualquer material e 
pessoas que tenham boa vontade para ministrar aulas para outras "destituídas de saberes". Contudo, fazemos a ressalva de que esse é um terreno de múltiplos saberes, singulares e plurais, e com o qual buscamos estabelecer um diálogo, a fim de contribuir para que possa se efetivar como campo de direito e de responsabilidade pública (Arroyo, 2006).

Acreditando nessa possibilidade, iniciamos um diálogo com a equipe técnica da EJA, vinculada à Secretaria Municipal de Educação de Salvador, movidas pela inquietação com o lugar secundarizado que a modalidade tem ocupado entre as políticas educacionais do referido município. Desse modo, inicialmente estabelecemos a parceria entre a Faculdade de Educação (FACED/UFBA) com a Equipe Técnica e Pedagógica da Secretaria de Educação do Município de Salvador (SMED) para a construção de um projeto de extensão de formação continuada intitulado Tecendo saberes na EJA: concepçóes na perspectiva da práxis. $\mathrm{O}$ referido projeto, em desenvolvimento, tem o objetivo de atender demandas formativas de coordenadores(as) da Gerência Regional de Educação do Município de Salvador; coordenadores(as) de escolas de EJA; equipe técnica e pedagógica da Secretaria de Educação do Município de Salvador (SMED) — todos ligados à referida modalidade da educação básica.

Um fenômeno que tem preocupado estudantes, professores, gestores, pesquisadores e impactado a oferta de escolarização para jovens, adultos e idosos é o fechamento de salas de aula e de escolas de educação de jovens e adultos no município de Salvador. Sabemos que esse não é um fenômeno exclusivo desse município, mas atinge várias cidades no território brasileiro, ${ }^{1}$ no interior e nas capitais. Em alguns casos, os argumentos das Secretarias de

1. Temos informação sobre o referido fenômeno em outras capitais brasileiras, a exemplo de Porto Alegre, Belo Horizonte, entre outras. 
Educação recaem sobre a chamada baixa frequência de estudantes da EJA; em outros casos culpabilizam os docentes e suas práticas como fator de desestímulo dos estudantes; em outros casos ouvimos justificativas que colocam a responsabilidade sobre os estudantes da EJA pela baixa frequência ou mesmo desinteresse.

No projeto de pesquisa intitulado Educação de jovens e adultos: concepçôes, avaliaçôes e políticas públicas no município de Salvador$-B A$, buscamos analisar a EJA no município de Salvador, Bahia, como campo de direito e responsabilidade pública. Para isso pretendemos: 1) compreender a EJA no município, retomando aspectos da trajetória dessa modalidade de educação; 2) mapear o analfabetismo e a baixa escolaridade no município; 3) construir o perfil dos sujeitos envolvidos na EJA da rede municipal de educação; 4) descrever condiçóes de oferta da educação na referida modalidade; 5) identificar quais políticas públicas/políticas educacionais foram implementadas na EJA no âmbito municipal; e, finalmente, 6, compreender a concepçáo de avaliação de aprendizagem presente nos documentos legais da educação e situar a prática avaliativa na EJA.

\section{A EJA e as perspectivas de mudanças no ensino de Salvador}

A EJA é aqui compreendida como modalidade da educação básica que se constitui em um campo de direito e de responsabilidade pública (Arroyo, 2006). Essa modalidade foi prevista na Lei de Diretrizes e Bases da Educação Nacional (LDB n. 9.394/96), especificamente em seu art. 37 que prevê a oferta da educação escolar para aqueles que náo tiveram acesso ou continuidade de estudos, no ensino fundamental e médio, na infância e na adolescência. Convém destacar que, na atualidade, a EJA enfrenta mudanças substanciais no que se refere à caracterização do seu público. Além da presença de adultos e idosos com pouca ou 
nenhuma trajetória escolar, a atual situação da modalidade comporta a presença de pessoas cada vez mais jovens, o que denominamos de jovens-adolescentes, que tiveram acesso à escolarizaçáo na infância, porém apresentam trajetórias escolares truncadas, não conseguiram consolidar a base alfabética, e outros importantes elementos no processo de aprendizagem.

O Brasil apresenta, ainda, um significativo contexto de desigualdade no acesso à educação básica, marcada pelas diferenças regionais, sociais, raciais, étnicas, geracionais, de gênero e culturais, conforme salientam Arroyo (2006) e Galvão e Di Pierro (2006).

Gráfico 1: Representaçóes da taxa de analfabetismo 2004-2014 / quinze anos ou mais de idade
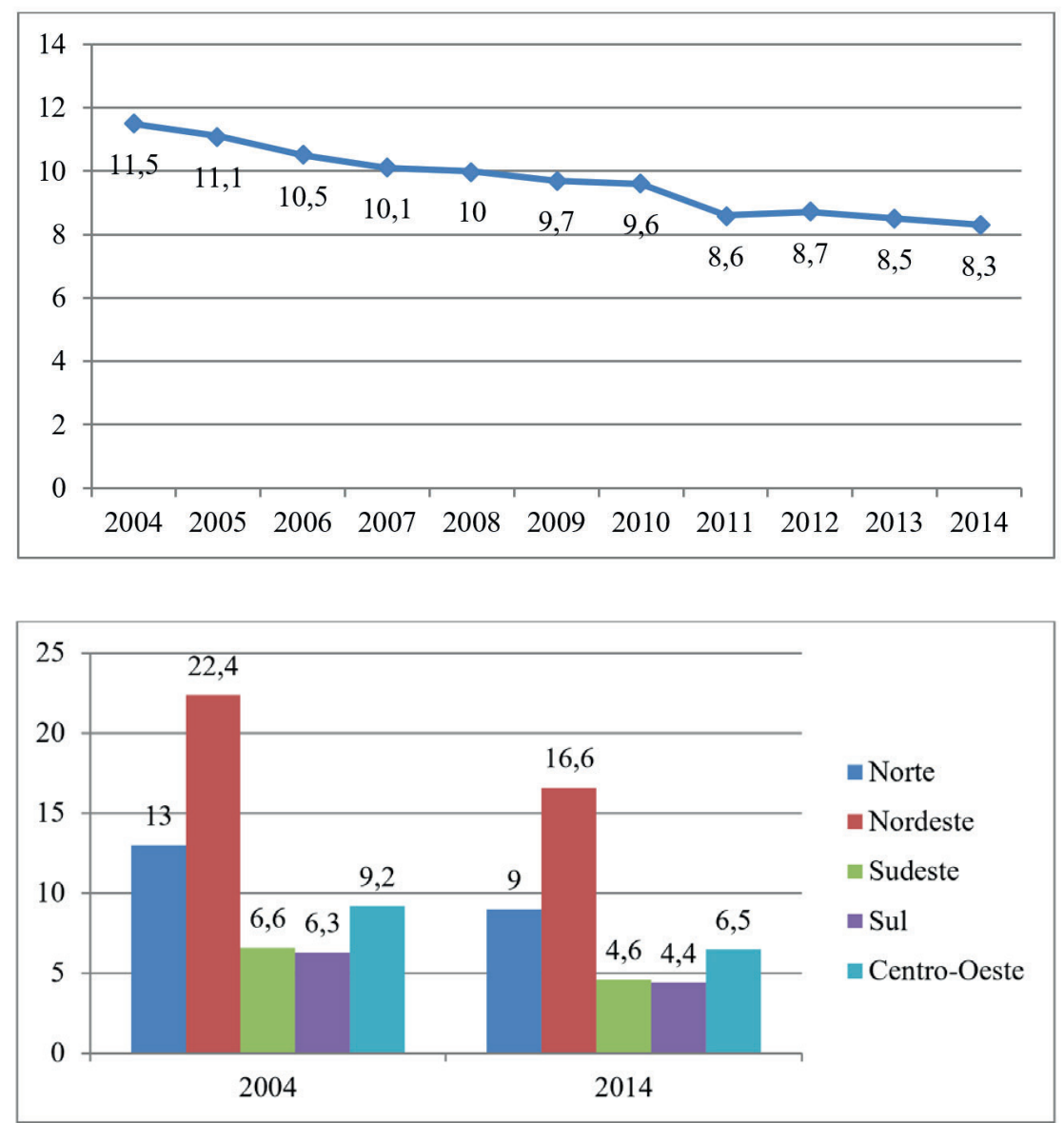

Fonte: IBGE-PNAD, 2015. 
Quando analisamos as informações apresentadas no gráfico 1, observamos uma redução na taxa de analfabetismo da população de quinze anos de idade ou mais, ao longo de uma década. No Brasil, o percentual de analfabetos em 2004 era de 11,5\% e em 2014 foi reduzido para 8,3\%, mas ainda se configura como enorme desafio à garantia do direito à educação para todos(as), conforme previsto na Constituição Federal de 1988 e na LDB n. 9.394/96. Os dados também mostram a permanência da disparidade regional ao longo do período, entre os quais se destaca a regiáo Nordeste com o maior índice $(16,6 \%)$ de analfabetos, com idade igual ou superior a quinze anos, os quais não tiveram acesso à escolarizaçáo ou que, mesmo tendo frequentado a escola, em algum momento, náo construíram efetivamente a habilidade de leitura e escrita.

Esse contexto de baixa escolaridade tem-se configurado também como marca em estados de algumas regióes do país. Nesse cenário, destacamos a Bahia que, segundo o IBGE (2013), apresentava uma populaçáo de 8.941 .000 pessoas com 25 anos ou mais, e $51 \%$ desse total náo completou oito anos de escolaridade, conforme tabela 1 .

Tabela 1: Pessoas de 25 anos ou mais de idade, total e respectiva distribuição percentual, por grupos de anos de estudo - enfoque Regiáo Nordeste e Regiōes Metropolitanas - 2013

\begin{tabular}{|c|c|c|c|c|c|c|c|c|c|}
\hline \multirow{2}{*}{$\begin{array}{c}\text { Regiáo Nordeste } \\
\text { e Regióes } \\
\text { Metropolitanas }\end{array}$} & \multicolumn{7}{|c|}{ Dessoas de 25 anos ou mais de idade } \\
\cline { 2 - 10 } & $\begin{array}{c}\text { Total (1 } \\
\mathbf{0 0 0} \text { pes- } \\
\text { soas) (1) }\end{array}$ & $\begin{array}{c}\text { Sem ins- } \\
\text { truçáo e } \\
\text { menos } \\
\text { de 1 } \\
\text { ano }\end{array}$ & $\begin{array}{c}\mathbf{1} \text { a 3 } \\
\text { anos }\end{array}$ & $\begin{array}{c}\mathbf{4} \text { a } 7 \\
\text { anos }\end{array}$ & $\begin{array}{c}\mathbf{8} \\
\text { anos }\end{array}$ & $\begin{array}{c}\mathbf{9} \text { e } \\
\mathbf{1 0} \\
\text { anos }\end{array}$ & $\begin{array}{c}\mathbf{1 1} \\
\text { anos }\end{array}$ & $\begin{array}{c}\mathbf{1 2} \text { a } \\
\mathbf{1 4} \\
\text { anos }\end{array}$ & $\begin{array}{c}\mathbf{1 5} \\
\text { anos } \\
\text { ou } \\
\text { mais }\end{array}$ \\
\hline Brasil & 123275 & 12,2 & 9,3 & 21,9 & 10,1 & 3,9 & 24,5 & 5,7 & 12,2 \\
\hline Nordeste & 32367 & 20,8 & 12,7 & 20,4 & 8,0 & 4,0 & 21,8 & 4,0 & 8,0 \\
\hline
\end{tabular}


46 Aprendizados ao longo da vida

\begin{tabular}{|c|c|c|c|c|c|c|c|c|c|}
\hline Maranhão & 3536 & 26,1 & 14,0 & 18,6 & 7,8 & 4,0 & 19,4 & 3,1 & 6,8 \\
\hline Piauí & 1816 & 23,8 & 16,5 & 20,6 & 7,2 & 4,0 & 16,4 & 3,3 & 8,0 \\
\hline Ceará & 5094 & 20,9 & 11,4 & 19,6 & 9,8 & 3,9 & 22,5 & 4,1 & 7,4 \\
\hline $\begin{array}{c}\text { Região Metropo- } \\
\text { litana } \\
\text { de Fortaleza }\end{array}$ & 2592 & 11,8 & 8,5 & 19,3 & 11,2 & 4,8 & 28,5 & 5,4 & 10,1 \\
\hline $\begin{array}{c}\text { Rio Grande do } \\
\text { Norte }\end{array}$ & 2028 & 19,8 & 11,9 & 19,3 & 7,7 & 5,0 & 22,9 & 3,8 & 9,2 \\
\hline $\begin{array}{c}\text { Paraíba } \\
\text { Pernambuco }\end{array}$ & 2323 & 21,7 & 14,3 & 21,1 & 7,1 & 3,8 & 17,7 & 4,3 & 10,1 \\
\hline $\begin{array}{c}\text { Regiáo Metropolita- } \\
\text { na de Recife }\end{array}$ & 2699 & 11,4 & 6,9 & 19,1 & 9,5 & 4,1 & 31,7 & 5,1 & 11,6 \\
\hline Alagoas & 1811 & 24,5 & 15,4 & 20,6 & 8,1 & 4,4 & 16,4 & 3,3 & 6,9 \\
\hline $\begin{array}{c}\text { Sergipe } \\
\text { litana } \\
\text { de Salvador }\end{array}$ & 1282 & 18,4 & 14,0 & 21,4 & 8,7 & 3,8 & 20,5 & 4,1 & 8,6 \\
\hline $\begin{array}{c}\text { Bahia } \\
\text { Regiáo Metropo- }\end{array}$ & 8941 & 19,7 & 11,9 & 20,7 & 7,1 & 4,2 & 24,1 & 4,4 & 7,6 \\
\hline
\end{tabular}

Fonte: IBGE, 2013.

Segundo a Tabela, em 2013, havia, na Regiáo Metropolitana de Salvador/BA, uma população de 2.663 .000 pessoas com idade igual ou superior a 25 anos. Desse total, $6,4 \%$ não tinha instruçáo ou estudou menos de um ano letivo; 6,2\% frequentou a escola entre um a três anos; $18 \%$ tinha entre quatro a sete anos de estudos. Portanto, totaliza-se $30,6 \%$ da populaçáo com menos de oito anos de escolarização. Foi em meio a esse cenário de baixa escolaridade da populaçáo jovem, adulta e idosa no Brasil, em particular no estado da Bahia, que as professoras investigadoras realizaram um projeto de pesquisa. O projeto articula atividades de ensino, pesquisa e extensão que pautam especificidades da educação de 
jovens e adultos e suas convergências e diálogos com políticas de educaçáo, educação popular. Também articula EJA como direito, educação profissional, formação de professores, avaliação da aprendizagem, entre outros temas. Busca não só compreender os desafios presentes no campo da EJA, como construir, com professores(as) da educação básica e estudantes, conhecimentos que possam contribuir para o enfrentamento desses desafios.

$\mathrm{O}$ projeto tem permitido discussóes que desconstroem a visão produzida historicamente de que a EJA é uma modalidade fadada ao fracasso e, em contrapartida, ampliam a ideia de que os sujeitos que a constituem possuem conhecimento de mundo, de cultura, de sociedade, de política, entre outros. Além disso, a EJA, vista como um campo de direito e de responsabilidade pública, provoca pensar açóes que contribuam para a melhoria da qualidade da educaçáo na referida modalidade.

A justificativa para estabelecermos parceria com a Equipe Técnica e Pedagógica da Secretaria de Educação (SMED) se deu, primeiramente, por termos conhecimento do cenário de baixa escolaridade da populaçáo jovem, adulta e idosa na Região Metropolitana de Salvador. Em segundo lugar, por identificarmos o processo de fechamento de turmas e escolas de EJA em diferentes bairros do município. Terceiro, porque nosso compromisso social e educacional nos instigou a contribuir com a produção do conhecimento, com a reconfiguração da EJA e a formação de profissionais para atuar nessa modalidade.

Algumas perguntas orientaram a construção da pesquisa, tais como: qual a situação do analfabetismo e da baixa escolaridade em Salvador? Quem são os analfabetos? Quantos são e onde estáo os jovens, adultos e idosos analfabetos e com baixa escolaridade no município? Quantas são e onde estáo as escolas de EJA em Salvador? Quais os níveis de educação ofertados? Quem são 
os estudantes, professores e coordenadores da EJA no município de Salvador? Como a avaliação aparece nas discussões da Secretaria Municipal de Educação? Que práticas avaliativas são utilizadas pelos profissionais que atuam na EJA? Quais políticas de alfabetização, educação e avaliação têm sido desenvolvidas pelo município? Quais cursos de formação foram ofertados em Salvador; com que formato, carga horária, abrangência e foco de discussão? Além disso, buscamos problematizar as inquietaçóes provocadas pela realidade da EJA no âmbito municipal vivenciadas por seus profissionais.

Em linhas gerais, essa parceria pode proporcionar estreitamento da relação escola-universidade, uma vez que nosso contato imediato tem sido com profissionais ligados à Secretaria Municipal de Educação. Isso tem permitido o conhecimento mais específico do contexto da EJA no município e possibilitado a produção de conhecimento na área de educação de jovens e adultos, e acreditamos que a médio e a longo prazo poderá provocar mudanças de concepção dessa modalidade, na perspectiva da práxis daqueles(as) que atuam diretamente com o(a) educando(a).

\section{Revisão teórica}

Do ponto de vista da legislação, podemos afirmar que, segundo o art. $37 \mathrm{da} \mathrm{lei,} \mathrm{a} \mathrm{EJA} \mathrm{aparece} \mathrm{como} \mathrm{processo} \mathrm{educativo,} \mathrm{"[...]}$ destinada àqueles que não tiveram acesso ou continuidade de estudos no ensino fundamental e médio na idade própria" (Brasil, 1996). ${ }^{2}$ E esse não acesso acontece pela oferta irregular de educação escolar para o povo, ou pelas inadequaçóes dos sistemas escolares às necessidades das classes populares (nos seus tempos,

2. Embora esteja presente na legislação, problematizamos a ideia de que existe idade própria para aprender e se escolarizar. Entendemos que todas as idades são idades próprias para aprendizagens e escolarização. 
espaços e conteúdos), ou pelas condições socioeconômicas desfavoráveis para esse público.

A partir desse ponto de vista, entende-se que a EJA deve ser um processo educacional especificamente pensado para uma parcela da população que apresenta, além de um recorte cronológico peculiar, também características culturais específicas, marcadas pela exclusão. No art. 37, $\$ 1$. $^{\circ}$ da LDB n. 9.394/96 essa especificidade é reafirmada.

Os sistemas de ensino asseguraráo gratuidade aos jovens e aos adultos que náo puderam efetuar os estudos na idade regular, oportunidades educacionais apropriadas, consideradas as características do alunado, seus interesses, condiçóes de vida e de trabalho, mediante cursos e exames (Brasil, 1997, p. 174).

Ainda no art. 37, $\$ 2 .^{\circ}$ aparece: “[...] o Poder Público viabilizará e estimulará o acesso e a permanência do trabalhador na escola, mediante açóes integradas e complementares entre si" (Brasil, 1997, p. 175). Mas, segundo Haddad (1997), é com essa lei que o cenário de desvalorização da EJA e sua transformação em educação de segunda classe se completam. A LDB não deixa de tratar da temática, entretanto a trata de forma parcial, priorizando o ensino fundamental para crianças.

Vale ainda ressaltar que "[...] a Lei também manteve a ênfase nos exames supletivos e rebaixou a idade mínima para a certificação, de 18 para 15 anos no ensino fundamental e de 21 para 18 anos no ensino médio" (Di Pierro et al, 2001, p. 67). Outro dado relevante é a ausência, na $\mathrm{LDB}$, da questão do analfabetismo, o que dá a impressão de que esse não era um problema que atingia e que ainda assola o país.

Outro documento importante no cenário e na história da EJA, no Brasil, é o das Diretrizes Curriculares Nacionais para a 
Educação de Jovens e Adultos (Brasil, 2000a). Nesse documento, a EJA é entendida como uma modalidade da educação básica, nas suas etapas fundamental e média.

Mas, pergunta Arroyo (2001), como equacionar essa proposta de EJA, como modalidade da educação básica, sem perder todo o legado histórico de construção de uma educação que tem como referência básica os educandos, na condição de excluídos, marginais, oprimidos, empregáveis, miseráveis?

Para esse autor, é necessário rememorar o legado radical deixado pela educação popular e pela EJA ao longo da sua história; é preciso compreender que a sua atualidade se apresenta na condição social e humana dos jovens e adultos que inspiraram as experiências dos anos 1950 e 1960 (Arroyo, 2001).

$\mathrm{O}$ autor afirma que os princípios e as concepçôes que inspiraram as experiências de educação popular e EJA na década de 1960 "[...] continuam tão atuais em tempos de exclusão, miséria, desemprego, luta pela terra, pelo teto, pelo trabalho, pela vida. Tão atuais que não perdem sua radicalidade, porque a realidade vivida pelos jovens e adultos populares continua radicalmente excludente" (Arroyo, 2001, p. 11).

Ele alertava, na ocasião da aprovação das Diretrizes, para o fato de que, ao considerar a EJA como modalidade na educação básica, corria-se o risco de colocá-la dentro da estrutura do ensino fundamental e médio, com suas grades curriculares, cargas horárias e regimentos. Para o autor, fazer isso seria negar, esquecer, desconsiderar uma tradiçáo que aprendeu a educar fora das grades. Seria o equivalente a romper com uma tradição que tem como ponto de partida o educando e náo o ensino.

Ao retomar esse debate, Arroyo (2006, p. 47) ressalta a necessidade de reconfiguração da EJA em um processo - que já vinha ocorrendo - de ampliação da oferta pelos sistemas educacionais, resultado da longa luta de diferentes movimentos sociais de 
trabalhadores e trabalhadoras do campo e da cidade, e alerta que a EJA interroga o sistema escolar. Para o referido autor, "[...] a EJA não foi inventada para fugir do sistema público, mas porque neste não cabiam as trajetórias humanas dos jovens e adultos populares". No esforço de reconfiguração da EJA, é necessário um aprendizado mútuo, da EJA e dos sistemas escolares, e ressalta:

A EJA tem a aprender com a pluralidade de propostas de inovação educativa que vem acontecendo no sistema escolar assim como este tem muito a aprender com os corajosos esforços que vêm acontecendo na pluralidade de frentes onde se tenta, com seriedade, garantir o direito à educaçáo, ao conhecimento, à cultura dos jovens e adultos populares (Arroyo, 2006, p. 47).

Segundo as Diretrizes Curriculares Nacionais, a EJA representa uma dívida social para com as populaçóes jovem e adulta que não tiveram "[...] acesso e nem domínio da escrita e leitura como bens sociais, na escola ou fora dela e tenham sido a força de trabalho empregada na constituição de riquezas e na elevação das obras públicas" (Brasil, 2000, p. 5).

Um aspecto considerado importante por Soares (2002) é o fato de, nesse documento, a EJA não ter mais a função de suprir, de compensar a escolaridade perdida, como na legislação anterior. Pois, segundo esse documento,

São três as funçóes estabelecidas para a EJA: a função reparadora, que se refere ao ingresso no circuito dos direitos civis, pela restauração de um direito negado; a função equalizadora, que propóe garantir uma redistribuição e alocação em vista de mais igualdade de modo a proporcionar maiores oportunidades, de acesso e permanência na escola, aos que até então foram mais desfavorecidos; por último, a função, por excelência da EJA, permanente, descrita no documento como a funçáo qualificadora. É a funçáo que corresponde às necessidades de atualizaçáo e de aprendizagens contínuas, próprias da era em que nos encontramos (Soares, 2002, p. 13, grifo nosso). 
A heterogeneidade é a marca fundamental do público da EJA — adolescentes, jovens, adultos e idosos —, com suas múltiplas experiências de trabalho, de vida e de situação social. Dessa forma, faz-se necessária uma contextualização, a fim de que esse público possa dispor de modos diversos do seu tempo e do seu espaço na EJA (Brasil, 2000, p. 54).

As Diretrizes tratam ainda da necessidade de flexibilidade curricular, na qual as experiências que os alunos trazem consigo sejam aproveitadas pela escola, e que temas da vida cotidiana, a exemplo do trabalho, possam se tornar elementos geradores de um currículo pertinente.

Somado à reflexão de que é necessário um currículo que tenha significado para a EJA, também é verdadeiro que as práticas avaliativas devem favorecer a inclusáo do sujeito no processo de construção de aprendizagens. A avaliação da aprendizagem consiste na ação de acompanhar as produções do sujeito e, percebendo seu desenvolvimento, deveráo ser retomadas decisóes para que seja melhorado o processo de ensinar e de aprender.

$\mathrm{O}$ ato avaliativo não se vincula a um dia fixo tampouco a atividades pontuais. A isso dá-se o nome de exame. O seu contrário é a avaliaçáo que ocorre no cotidiano, acompanhando as produçóes e o desenvolvimento das aprendizagens.

Entendo a Avaliaçáo como algo inerente aos processos cotidianos e de aprendizagem, na qual todos os sujeitos desses processos estáo envolvidos, [...] a avaliação na escola não pode ser compreendida como algo à parte, isolado, já que tem subjacente uma concepção de educação e uma estratégia pedagógica (Freitas e Fernandes, 2007, p. 18).

Conforme trazem os autores, a avaliação não é uma ação dissociada da rotina da escola, descolada da atividade de ensino. Ela depende de objetivos claros ligados à aprendizagem, de critérios 
avaliativos vinculados diretamente aos objetivos propostos, devendo-se ainda compreender o contexto e tomar decisóes sobre quais instrumentos melhor contribuiráo para promover a aprendizagem.

Avaliar também deve ter como premissa a contribuiçáo para a formação integral do sujeito, inclusive para contribuir com a formação do trabalhador e da trabalhadora. Isso náo pode se perder de vista no contexto da EJA.

Ao considerar o trabalho como um elemento importante do componente curricular, as Diretrizes Curriculares destacam que, seja pela experiência, seja pela necessidade imediata de inserçáo profissional, o mesmo merece especial destaque. E continua.

A busca da alfabetização ou da complementação de estudos participa de um projeto mais amplo de cidadania que propicie inserção profissional e busca de melhoria das condiçóes de existência. Portanto, o tratamento dos conteúdos curriculares não pode se ausentar desta premissa fundamental, prévia e concomitante à presença em bancos escolares: a vivência do trabalho e a expectativa de melhoria de vida. Esta premissa é o contexto no qual se deve pensar e repensar o liame entre qualificação para o trabalho, educação escolar e os diferentes componentes curriculares (Brasil, 2000, pp. 54-5).

O documento continua citando o art. 41 da LDB, no qual "[...] o conhecimento adquirido na educação profissional, inclusive no trabalho, poderá ser objeto de avaliação, reconhecimento e certificação para prosseguimento ou conclusão de estudos" (Brasil, 2000, p. 55).

E completa destacando que o projeto pedagógico e a formação dos docentes da EJA devem considerar, "[...] sob a ótica da contextualização, o trabalho e seus processos e produtos desde a mais simples mercadoria até os seus significados na construção da vida coletiva”. Conclui que “[...] as múltiplas referências ao trabalho constantes na LDB têm um significado peculiar para quem já é trabalhador" (Brasil, 2000, p. 55). 
Quando estudamos a história da educação de jovens e adultos observamos que o perfil dos professores que trabalharam na EJA era de "[...] estudantes em processo de habilitaçáo para o magistério, agentes comunitários e voluntários com distintos níveis de escolaridade" (Di Pierro, 2011, p. 167). Esse dado nos provoca pensar, discutir e propor movimentos em prol da formaçáo de profissionais para atuar nesse campo do conhecimento.

Nesse contexto, vale a pena trazer para essa discussão elementos que dialoguem sobre como os cursos de pedagogia têm preparado os professores para atuarem na EJA e quais problematizações, teorizaçóes, práticas têm sido proporcionadas aos estudantes que possivelmente atuarão nessa modalidade de ensino.

Para Moura (2009) e Soares (2011), a falta de qualificação é uma das muitas barreiras encontradas pelo professor da EJA e suas consequências apresentam-se nas açôes pedagógicas desenvolvidas, alheias às especificidades e às peculiaridades dessa modalidade de ensino. Ressalta-se que as disciplinas oferecidas pelos cursos de pedagogia (nem todos os cursos) náo dáo conta de trazer aspectos importantes que permitam conhecer melhor a EJA, favorecendo um trabalho pedagógico comprometido.

A realidade da EJA é preocupante, como já sinalizava a professora Tânia Moura (2009), que coordenou uma investigação realizada pelo Programa Institucional de Bolsas de Iniciação Científica (Pibic) pela Universidade Estadual de Alagoas (Uneal), no período compreendido entre agosto de 2008 a agosto de 2009; essa autora deparou-se com uma açáo pedagógica desarticulada que sinalizava a carência formativa. Assim, descreveu: "[...] em uma de nossas investigaçóes realizada numa turma da $3^{a}$ fase do $1^{\circ}$ segmento de EJA, a professora fotocopiava os textos do livro de sua filha de 5 anos, que estudava numa escola da rede particular, para utilizar com seus alunos" (Moura e Ribeiro, 2011, p. 61). 
Esse exemplo mostra que devemos pensar na discussão sobre a realidade dessa modalidade, considerando especificidades para trabalhar currículo, metodologias, processos avaliativos e a dinamização do ensino. A análise feita pela pesquisadora permitiu concluir que a professora náo percebia diferença entre a forma de aprender de um adulto e a de uma criança, ou náo valorizava o conhecimento acumulado. Isso reflete a necessidade de formaçáo, de saberes de outras áreas do conhecimento, como a psicologia e a sociologia, para que se tenha o entendimento de que as estruturas mentais, os procedimentos, as relaçóes, a elaboração de conceitos e o tempo de aprendizagem acontecem de modo diferente entre crianças e adultos. Do contrário, teremos sérios problemas sociológicos e pedagógicos.

É evidente que os problemas pedagógicos (a matéria a ensinar, os currículos, os métodos) correspondentes a cada faixa etária são distintos. Por isso a alfabetização do adulto é um processo pedagógico qualitativamente distinto do infantil (a não ser assim, cairíamos no erro da infantilização do adulto) [...] (Pinto, 2010, p. 74).

Essa afirmação é compatível com o que estamos defendendo enquanto formaçáo que vise à aprendizagem significativa, ocorrendo dentro de contexto próprio do cotidiano do adulto, em que, além de se reconhecer enquanto agente ativo, também crie estratégias de resolução e de tomada de decisóes no contexto real. Esse modo de olhar para o mundo do adulto (inclui-se em nossa pesquisa todos aqueles que passaram da fase da infância) foi cuidadosamente registrado na obra Sete liçóes sobre educação de adultos, da autoria de Álvaro Vieira Pinto, intelectual e filósofo brasileiro. Essa obra, além de ter sido a última que o autor publicou em vida, traz contribuiçóes acerca da experiência e das reflexóes de aulas ministradas para adultos. 
Corroborando a ideia de pensar uma formação de professores e professoras que entendam melhor a realidade da EJA, Barcelos (2009, p. 30) assinala:

A nossa formação como educadores e educadoras passa, necessariamente, pelo nosso cotidiano. Ela - a formação docente - está intimamente ligada aos nossos costumes, hábitos, conceitos, preconceitos. Tem muito que ver com nossas representaçôes e nosso imaginário social vigente. Enfim, formação e experiência são irmãos inseparáveis.

A formação a qual se fez referência é aquela que acontece independentemente de sistemas formais de ensino ou também que poderá se constituir entre o local de trabalho do professor e da professora (a escola) e a Universidade. E foi nesse contexto que pensamos a articulaçáo e parceria entre a equipe de EJA do município de Salvador e as professoras pesquisadoras da FACED/ UFBA, de que esperamos ter tirado liçóes de aprendizagem nesse movimento formativo.

\section{Pressupostos e procedimentos metodológicos}

Os pressupostos metodológicos que sustentaram este estudo têm sua base no método dialético, enveredando pela pesquisa qualitativa, com os princípios da pesquisa colaborativa. Em termos de instrumentos para a construção de informações a partir da pesquisa documental, utilizamos entrevista, fonte oral, estudo de caso e grupo focal. Para analisar tais informaçóes, fizemos uso da técnica de análise de conteúdo.

A construçáo desse caminho investigativo pressupôs uma perspectiva dinâmica e histórica. Por isso tomamos o método dialético como eixo estruturante desse trabalho, porque viabiliza a construção do conhecimento sem adotar uma forma linear, mas 
considera as contradiçóes que marcam o contexto que será investigado. Assim, entendemos que o melhor modo de investigação será pela abordagem dialética.

A dialética é um modo de filosofar que pretende construir o conhecimento a partir da contradição, da argumentação. Sua abordagem segue várias perspectivas e é identificada, como, por exemplo, dialética de Sócrates, de Platão, de Aristóteles, de Hegel, de Marx. Aqui não temos a pretensão de criticar ou discordar de nenhuma dessas abordagens, pois cada uma tem sua contribuição para a filosofia, a história e a ciência.

Vale dizer que adotamos uma perspectiva freireana para pensar as contradiçóes da educação e reconhecemos que em seus escritos existem fortes marcas das dialéticas de Hegel e de Marx, os quais influenciaram seu pensamento, principalmente no que concerne à sua práxis educativa. A esse respeito, no prefácio do livro Paulo Freire em diálogo com outros autores, organizado por Freitas et al (2014), o professor Streck reportou-se aos escritos de Freire da seguinte maneira:

As palavras de Paulo Freire traduzem bem a sua maneira de lidar com as ideias e opiniōes alheias, fossem essas de autores renomados ou de camponeses, de operários ou a de professores. Em sua vasta obra não encontramos um apego fanático a alguma teoria ou a uma defesa intransigente de algum autor. Sabemos que ele bebia de fontes marxianas, existencialistas, fenomenológicas, pragmatistas (escolanovistas), entre outras. Ele lançava mão da filosofia, da sociologia, da linguística, da teologia e de outras ciências com as quais se encontrou ao longo de sua trajetória de educador, que no seu caso significava ser um pensador da educação. Também não encontramos em seus livros grandes debates teóricos sobre a validade ou não de determinada teoria, ou o menosprezo de autores que expunham pensamentos diferentes (Streck, 2014, p. 5). 
O modo de se reportar a Freire resgata o jeito próprio do teórico quando organizava suas ideias a partir da contribuição das várias áreas do conhecimento, sem supervalorizar ou menosprezar uma ou outra. $\mathrm{O}$ que Freire pretendia nos seus escritos era mostrar que não há saberes maiores ou menores (nem de métodos nem de teorias), mas saberes diferentes, e não há problema em promover o diálogo entre estes, pois é possível o diálogo entre os diferentes, não entre os antagônicos.

Optamos pela pesquisa qualitativa do tipo colaborativa, pois, segundo Oliveira (2010, p. 37) trata-se de "[...] um processo de reflexão e análise da realidade através da utilização de métodos e técnicas para compreensão detalhada do objeto de estudo em seu contexto histórico e/ou segundo sua estruturação". Nessa abordagem, não se pode deixar de valorizar o contexto (pessoas, tempo e espaço) e a estrutura (organizaçóes de poder, sistematização, hierarquização). Por isso, na pesquisa qualitativa, são "elementos" importantes: o pesquisador, o pesquisado e o contexto no qual os sujeitos se inserem.

A pesquisa qualitativa nos possibilitou a compreensão do teor de complexidade em que se estrutura a educação, tornando o objeto ainda mais simples de ser entendido e estudado, ampliando as bases para que obtivéssemos dados claros a partir do posicionamento do pesquisador que procurou entender os fenômenos com a contribuição dos colaboradores.

$\mathrm{Na}$ abordagem colaborativa, "[...] o pesquisador não é um observador passivo que procura entender o outro, que também, por sua vez, não tem um papel passivo. Ambos são co-participantes [sic] ativos no ato da construção e de transformação do conhecimento" (Bortoni-Ricardo, 2008, pp. 71-2).

Nessa perspectiva, entendemos o contexto colaborativo como o mais propício para a construção sistemática do conhecimento, porque oportuniza aos colaboradores a troca de experiências, 
o questionamento de conceitos e de situaçóes-limite. Isso revela o papel que cada colaborador tem dentro do grupo, visto que a possibilidade de arguir, sugerir, expressar seu ponto de vista, confrontar ideias e reconstruí-las consiste no grande diferencial dos grupos colaborativos.

Portanto, pesquisador e pesquisados são parceiros, com objetivos e papéis definidos e se propóem em trazer para o rol de discussóes as implicaçóes políticas e pedagógicas que interferem no processo de formação contínua dos professores atuantes na educação dos jovens e dos adultos. Esses profissionais, durante a pesquisa, estiveram "[...] na condição de agentes críticos, os colaboradores - sujeitos experientes e possuidores de conhecimento - participam ativamente do estudo" (Moura, 2010, p. 397). Tratou-se de um trabalho de investigação conjunta, que buscou informaçóes necessárias para estruturar e responder as inquietaçôes dos colaboradores e colaboradoras e das pesquisadoras, o que contribuiu para a caracterização da modalidade, facilitando a intervenção no contexto pesquisado.

A educação nos abre possibilidades investigativas que vão além de mera busca quantitativa de dados, mas nos permite, por intermédio da pesquisa qualitativa, criar espaços de colaboração, visto que "[...] no âmbito da educação, a pesquisa colaborativa é a atividade interativa de coprodução de saberes e desenvolvimento profissional realizado conjuntamente por pesquisadores e por professores de forma crítico-reflexiva" (Ibiapina, 2007, p. 22). Essa maneira crítico-reflexiva de coproduçáo de saberes e desenvolvimento profissional se traduz na não alienação, na não submissão ao controle ideológico, mas na liberdade de criar possibilidades de ascensão e autonomia intelectual.

As etapas que fundamentaram a pesquisa se constituíram de estudo teórico amplo acerca da EJA nos documentos oficiais da educação e dos teóricos da área. Em seguida, fizemos levanta- 
mento de dados estatísticos, pesquisa documental, questionários para gerentes regionais de ensino do município, vinculados à EJA, diálogos a partir das reunióes de trabalho, registros escritos e gravados dos momentos de formação durante os encontros nas atividades de extensão realizadas.

Aliada a essas açóes, realizamos entrevistas com os profissionais mais antigos, a fim de reconstruir as memórias da EJA no município, o que também permitiu conhecermos as condiçóes de oferta da educação na modalidade. Outra etapa ocorreu a partir do estudo de uma das Regionais de ensino do município de Salvador, para nos aproximarmos e compreendermos melhor como se desenvolvia o trabalho envolvendo ensino, avaliação e aprendizagem naquele contexto.

De posse de todo esse material, começamos outra etapa de organização e análise das informaçóes, utilizando o procedimento de análise de conteúdo estudado por Bardin (2011, p. 48), que traz a seguinte definição:

Um conjunto de técnicas de análise de comunicaçóes visando obter por procedimentos sistemáticos e objetivos de descrição do conteúdo das mensagens indicadores (quantitativos ou náo) que permitam a inferência de conhecimentos relativos às condiçóes de produção/recepção (variáveis inferidas) dessas mensagens.

Por isso, foi importante estarmos atentas às expressões faladas e escritas, a fim de nos aproximarmos da compreensão real do contexto e das condiçóes em que foram elaboradas as mensagens emitidas pelos colaboradores e pelas colaboradoras da pesquisa. Isso nos remeteu às significaçóes, ao modo como poderiam ocorrer as falas que, carregadas de conteúdo, poderiam sinalizar uma mensagem. O papel do analista de conteúdos (pesquisadores/as) é o de compreender o sentido da comunicação e perceber a signi- 
ficação que está implícita na fala. Por isso, diz-se que o objetivo desse tipo de técnica consiste na inferência - na deduçáo.

Esse conjunto de técnicas envolveu etapas analíticas de investigação e incluiu a descrição objetiva e sistemática do conteúdo expresso na comunicação, a fim de interpretá-lo. Por isso, o analista tem um trabalho semelhante a de um detetive, porque procura vestígios (Bardin, 2011) na comunicação, no conteúdo da mensagem. Contudo, faz-se necessário codificar o texto para analisá-lo. Isso implica a organizaçáo do texto em categorias.

De acordo com Bardin (2011, p. 43), a análise categorial “[...] pretende tomar em consideração a totalidade de um 'texto', passando-o pelo crivo da classificaçáo e do recenseamento, segundo a frequência de presença (ou de ausência) de itens de sentido". Nesse aspecto, o conjunto de informaçóes construído por meio do questionário, da entrevista, da fotografia e filmagem, do diálogo na formação - no curso de extensão, no grupo focal — consistiu no texto condensado e alocado em categorias de análise.

O objetivo da análise de conteúdo é manipular as mensagens (conteúdo e sua expressão), a fim de mostrar evidências que permitam inferir sobre outra realidade exterior àquela, ou seja, é a busca de significaçóes acerca de uma realidade que não se mostra de imediato, mas tem que ser encontrada no interior da mensagem dos colaboradores e das colaboradoras.

Em tempo, destacamos que esses e essas colaboradores/colaboradoras faziam parte das Gerências Regionais de Salvador, dos seguintes bairros: Centro, Liberdade, São Caetano, Orla, Cabula, Pirajá, Itapuã, Cajazeiras, Subúrbio I e II.

Essas informaçóes iniciais acerca da EJA foram disponibilizadas pela equipe técnica da Secretaria de Educação de Salvador, com a qual estivemos em parceria no curso de extensão em educação de jovens e adultos. 


\section{Consideraçóes e expectativas}

Os resultados parciais apontam para uma baixa escolaridade na regiáo metropolitana de Salvador. A referida regiáo apresenta dados de $6,4 \%$ de pessoas náo alfabetizadas e um percentual de $30,6 \%$ de baixa escolaridade entre adolescentes, jovens, adultos e idosos. Além disso, o processo de fechamento de salas de aula e de escolas de EJA na cidade de Salvador coloca o desafio de compreender melhor esse fenômeno, frente ao conceito de EJA como campo de direito e de responsabilidade pública.

Esses dados referentes à baixa escolaridade estáo sendo cruzados com outros dados que nos possibilitaráo identificar quem são esses sujeitos, onde estáo localizados na cidade e onde estáo as ofertas da referida modalidade de educaçáo. Ao mesmo tempo, estamos levantando dados sobre a história recente das políticas de EJA no referido município, e construindo um perfil dos professores e das professoras do ponto de vista da formaçáo, gênero, idade, pertencimento étnico-racial, entre outros.

Quanto à formação continuada e em serviço dos professores da referida modalidade é possível informar que, ao longo do ano de 2017, a única ação de formaçáo desenvolvida foi o projeto Tecendo saberes na EJA: concepçóes na perspectiva da práxis, uma parceria da FACED/UFBA com a SMED/Salvador, no âmbito da extensão universitária.

Para além dessa ação extensionista, buscamos nos reunir com as profissionais da SMED a cada quinze dias para dialogar sobre as demandas dessa modalidade, mas também para aprofundarmos os conhecimentos acerca da EJA no município, com o objetivo de fundamentar a pesquisa em curso. A esse respeito, reiteramos que o referido projeto, iniciado em agosto de $2017 \mathrm{com}$ previsáo de conclusáo em dezembro de 2019, traz a expectativa de aprofundar o diálogo e estreitar a parceria com a Secretaria de 
Educação para pensarmos caminhos de fortalecimento da EJA para a afirmação da educação como direito nessa modalidade de ensino.

\section{Referências}

ALVARES, Sonia Carbonell. "Educação estética para jovens e adultos". V Seminário Nacional de Formação de Educadores de Jovens e Adultos, Campinas, 13-15 maio 2015. Unicamp.

ARROYO, Miguel González. "Educação de Jovens-Adultos: um campo de direitos e de responsabilidade pública". In SOARES, Leôncio et al (orgs.). Diálogos na educação de jovens e adultos. 2 ed. Belo Horizonte: Autêntica, 2005, pp. 19-50.

. "A educação de jovens e adultos em tempos de exclusão". Alfabetização e Cidadania: Revista de Educação de Jovens e Adultos. n. 11, São Paulo, abr. 2001, pp. 9-20.

BARCELOS, Valdo. Formação de professores para educação de jovens e adultos. 3 ed. Petrópolis, Rio de Janeiro: Vozes, 2009.

BARDIN, Laurence. Análise de conteúdo. São Paulo: Ediçóes 70, 2011.

BORTONI-RICARDO, Stella Maris. Introdução à pesquisa qualitativa. São Paulo: Parábola Editorial, 2008.

BRASIL. "Lei n. 9.394 de 20 de dezembro de 1996". Estabelece as Diretrizes e Bases da Educação Nacional. Brasília: Congresso Nacional, 1996.

. IBGE-PNAD. A janela para olhar o país. Brasília: 2014. Disponível em: http://www.ibge.gov.br/home/presidencia/noticias/imprensa/ppts/00 000024052411102015241013178959.pdf. Acesso em 7 jul. 2017.

. "Resoluçáo CNE/CEB n. 1, de 5 de julho de 2000". Estabelece as Diretrizes Curriculares Nacionais para a Educação e Jovens e Adultos. Brasília: 2000.

BRZEZINSKI, Iria. (org.). LDB interpretada: diversos olhares se entrecruzam. São Paulo: Cortez, 1997. 
DI PIERRO, Maria Clara. "Balanço e perspectivas da pesquisa sobre formação de educadores(as) de jovens e adultos". In III Seminário nacional de formação de educadores de jovens e adultos. Porto Alegre, Rio Grande do Sul: Deriva, 2011, pp. 167-77.

e HADDAD, Sérgio. “Transformaçôes nas políticas de Educação de Jovens e Adultos no Brasil no início do terceiro milênio: uma análise das agendas nacional e internacional". Cad. Cedes, v. 35, n. 96, Campinas, maio-ago, 2015, pp. 197-217.

FREITAS, Luiz Carlos de e FERNANDES, Cláudia de Oliveira. Indagaçôes sobre currículo: currículo e avaliação. Brasília: Ministério da Educação, Secretaria de Educaçáo Básica, 2007.

GALVÃO, Ana Maria de Oliveira e DI PIERRO, Maria Clara. Preconceito contra o analfabeto. 2 ed. Sáo Paulo: Cortez, 2013.

HADDAD, Sérgio. "A educaçáo de pessoas jovens e adultas e a nova LDB". In IBIAPINA, Ivana Maria Lopes de Melo (org.). A trama de pesquisar e formar em colaboração. Texto e contexto. Belo Horizonte: Autêntica, 2007, pp. 107-23.

MOURA, Maria da Glória Carvalho. "Apercebendo-se da diferença: conhecendo os sentidos atribuídos pelos professores". In BOMFIM, Maria do Carmo Alves do et al (orgs.). Educação e diversidade cultural. Fortaleza: Edições UFC, 2010, pp. 391-406.

MOURA, Tânia Maria de Melo. "Formaçáo de educadores de jovens e adultos: realidade, desafios e perspectivas atuais". Revista Práxis Educacional, v. 5, n. 7, Vitória da Conquista, jul./dez. 2009, pp. 45-72. e RIBEIRO, Nadja Naira Aguiar. "O ponto cego da formação de professores da/para Educação de Jovens e Adultos". Debates em Educação, v. 3, n. 6, Maceió, ago./dez. 2011, pp. 53-69.

OLIVEIRA, Maria Marly de. Como fazer pesquisa qualitativa. 3 ed. Petrópolis, Rio de Janeiro: Vozes, 2010.

PEREIRA, Thiago Ingrassia et al (orgs.). Paulo Freire em diálogo com outros(as) autores(as). 1 ed. Passo Fundo: Méritos, 2014.

PINTO, Álvaro Vieira. Sete liçóes sobre educação de adultos. 16 ed. São Paulo: Cortez, 2010. 
SALES, Sandra R. e PAIVA, Jane. "As muitas invenções da EJA". Revista AAPE EEPA, v. 22, n. 58, jun. 2014.

SAVIANI, Demerval. A nova lei da educação: trajetórias limites e perspectivas. Campinas: Autores Associados, 1997.

SOARES, Leôncio. Educação de jovens e adultos. Rio de Janeiro: DP\&A, 2002. - "As especificidades na formaçáo do educador de jovens e adultos: um estudo sobre propostas de EJA.” Educação em Revista (UFMG. Impresso), v. 27, n. 2, Belo Horizonte, ago. 2011, pp. 303-22.

STRECK, Danilo Romeu. "Prefácio". In FREITAS, Ana Lúcia Souza de et al (orgs.). Paulo Freire em diálogo com outros autores. Passo Fundo: Méritos, 2014. 